\title{
Bioinformatics in Sri Lanka - Still in its infancy
}

Prof. Vajira H. W. Dissanayake MBBS, PhD.

Executive Editor, Sri Lanka Journal of Bio-medical Informatics

E-Mail address: vajirahwd@hotmail.com

Sri Lanka Journal of Bio-Medical Informatics 2012;3(1):1

DOI: http://dx.doi.org/10.4038/sljbmi.v3i1.5072

The first issue of every volume of the journal is a thematic issue in bioinformatics. We however find it difficult to obtain original articles for the issue. This is not surprising given the fact that bioinformatics in Sri Lanka is still in its infancy.

The need to develop bioinformatics in the country was discussed at the "Global Forum of Sri Lankan Scientists" in December 2011 organised by the National Science Foundation of Sri Lanka (see http://www.nsf.ac.lk). It would however depend on the development of high throughput genotyping and sequencing facilities in the country. Such facilities are not available in the country and the sequencing workload in the country is minute. There is simply not enough local work for bio-informaticians. Time would tell whether the steps taken by the National Science Foundation would yield results and the field of bioinformatics would grow.

In this issue we carry four review articles from four young bio-informaticians. They are on molecular biology databases ${ }^{(1)}$, identification of segmental duplications in the human genome $^{(2)}$, genome wide haplotype analysis ${ }^{(3)}$, and genome wide SNP discovery ${ }^{(4)}$. We hope that these articles will spur young researchers to develop an interest in bioinformatics and take up bioinformatics as a career.

\section{References}

1. Cooray MPNS. Molecular biological databases: evolutionary history, data modeling, implementation and ethical background. Sri Lanka Journal of Bio-Medical Informatics 2012; 3: 2-11

2. Fonseka A. Identification of segmental duplications in the human genome. Sri Lanka Journal of Bio-Medical Informatics 2012; 3: 12-19

3. Weerasekara VS. Genome-wide haplotype analysis. Sri Lanka Journal of Bio-Medical Informatics 2012; 3: 20-24

4. Kumanayake PHC. Genome-wide SNP discovery in associating with human diseases. Sri Lanka Journal of Bio-Medical Informatics 2012; 3: 25-31 